\title{
Comparative analysis on visual and olfactory signals of Papilio xuthus (Lepidoptera: Papilionidae) during foraging and courtship
}

Jie Liu

Chinese Academy of Forestry

Mingtao Li

Chinese Academy of Forestry

Shunan Chen

Chinese Academy of Forestry

Lei Shi

Chinese Academy of Forestry

Xiaoming Chen ( $\nabla$ cafcxm@139.com )

Chinese Academy of Forestry

\section{Research Article}

Keywords: visual and olfactory signals, Papilio xuthus (Lepidoptera: Papilionidae), foraging, courtship, butterfly

Posted Date: December 9th, 2020

DOl: https://doi.org/10.21203/rs.3.rs-118157/v1

License: (c) (i) This work is licensed under a Creative Commons Attribution 4.0 International License.

Read Full License 


\section{Abstract}

In this study, we examined the roles of visual and olfactory responses during foraging and courtship of the butterfly Papilio xuthus. Our results showed that $P$. xuthus was sensitive to color in the range of 350-

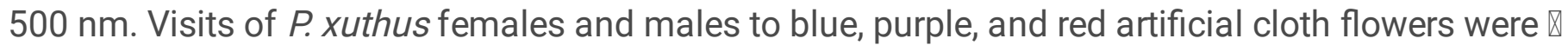
$54.90 \%$ and $\nabla 39.22 \%, \nabla 19.61 \%$ and $\nabla 35.29 \%$, and $\nabla 9.80 \%$ and $\nabla 19.61 \%$, respectively. Application of $10 \%$ honey on these artificial flowers resulted in an increase of 3.41 and 3.26 fold in flower visits by the butterfly in comparison with controls. When $10 \%$ honey water was sprayed on colorless artificial flowers, flower visits reduced seven fold for females and two fold for males, indicating that both visual and olfactory perceptions play important roles during foraging. During courtship, four types of chasing were observed in a natural population of $P$. Xuthus. The four types are males chasing females (49\%), males chasing males (25\%), females chasing males (13\%), and females chasing females $(10 \%)$. However, when odorless artificial mimics of butterflies were used, no significant differences were observed among these types of chasing, indicating that olfactory perception was crucial for the butterfly during courtship. Profiling volatile organic chemicals and individual bioassays revealed that a-farnesene might play an important role in distinguishing males from females during courtship of the butterfly.

\section{Main Text}

Visual and chemical cues are critical during butterfly foraging and courtship, but their roles vary in individual butterfly species. The eyes of most butterflies contain visual pigments that can sense a range of light spectrum including ultraviolet (300-400 nm), blue (400-500 nm), long-wave (500-600 nm), and red (760-622 nm $)^{1}$. During foraging, different taxa of butterflies use different visual cues to locate food source. Most butterflies prefer blue ${ }^{2}$, and some butterflies of Papilio and Pieris species prefer purple. Tirumala limniace and some Pieris and Vanessa prefer yellow, whereas Danaus chrysippus, Cethosia biblis and Cethosia cyane are more sensitive to red $^{2-8}$. During courtship, butterflies distinguish females from males of the same species primarily based on visual signals, including wing characteristics (color, spots, and size), wing surface reflection spectrum, and polarized light. Dichroic butterflies identify opposite sex by the color of wings under natural light ${ }^{9-10}$. Pieris rapae males identify females using visual cues of their wings ${ }^{11}$. Heliconius Cydno males recognize females by their polarized aurora ${ }^{12}$.

Chemical cues are also important in localizing food sources ${ }^{13-16}$. Butterflies can also distinguish the opposite sex from the same species as well as individuals from heterogenetic species based on chemical cues $^{17-20}$. Some butterflies, such as Kallima inachus and Danaus genutia, hardly have any vision. Therefore chemical signals are their only cues during foraging and courtship. VOCs from individual butterflies are critical for them to distinguish opposite sex from the same species and individuals from different species ${ }^{21-23}$. For example, VOCs from the females and males of Papilio machaon are significantly different and serve as important cues in identifying opposite sex from the same species ${ }^{24}$. 
Four types of relationships between visual and chemical communication have been identified during butterfly foraging and courtship: (1) vision was given priority over olfaction; (2) olfaction was given priority over vision; (3) olfaction and vision were equally important; and (4) only olfaction was used. However, what determines the contribution of visual and chemical perception in foraging and courtship is not yet clear.

In this study, we conducted a series of assays to determine the importance of visual and chemical cues for the butterfly $P$. xuthus during foraging and courtship. We used butterfly mimics to separate the impact of visual and chemical cues on butterfly foraging and mating behavior. We also analyzed wing color patterns between the females and males, profiles of VOCs from males and females, and tested selected individual VOCs on butterfly behavior. Our results represent an initial analysis on the contribution of visual and chemical cues to foraging and mating behavior in this butterfly species.

\section{Results}

\section{Response to visual and chemical cues during foraging}

Generally, males of most butterflies are more active than females during flower visits. However, both males and females of $P$. xuthus were very active during foraging. In the absence of any chemical cue, both females and males mainly visited blue (440-475 nm), purple (380-420 nm), and red flowers (615$630 \mathrm{~nm}$ ) (Fig. 2A-B). Together, $84.31 \%$ of flower visits by females and $94.12 \%$ of flower visits by males were to blue, purple, and red flowers. The preference of females and males toward flowers with these three colors was significantly different. Specifically, visits to blue, red, and purple flowers by females versus males were $54.90 \%$ versus $39.22 \%(F=12.34$; $d f=5.00 ; P<0.05) ; 9.80 \%$ versus $19.61 \%(F=9.38$, $d f=5.00 ; P<0.05)$; and $19.61 \%$ versus $35.29 \%(F=14.77, d f=5.00 ; P<0.05)$, respectively.

Chemical cues had a significant impact on butterfly behavior. After spraying $10 \%$ honey water on otherwise odorless, artificial flowers, total number of flower visits increased 3.33 times. More specifically, visits to flowers with honey water by females and males increased 3.41 and 3.26 times, respectively, in comparison to the same flowers without honey water (Fig. 2C). On the other hand, flower colors also impacted responses of butterflies to honey water. Total number of butterfly visits by both males and females increased 33.78 times to flowers applied $10 \%$ honey water in comparison with honey water alone controls. Males were more sensitive to flower and honey combinations than females, with 83.00 times increase in male visits and 24.85 times increase in female visits to flowers with $10 \%$ honey water than controls with $10 \%$ honey water alone (Fig $2 \mathrm{C}$ ). These results showed that $P$. xuthus relied on both visual and chemical cues during foraging.

\section{Response to color and odor during courtship}

Four types of chasing behavior of natural $P$. xuthus populations were observed during courtship, namely, males chasing females, males chasing males, females chasing males, and females chasing females (Fig. 3A). Nearly half (49\%) of chasings were males chasing females, but only $13 \%$ of chasings were 
females chasing males $(F=23.34, d f=5.00 ; P<0.01)$. Interestingly, there were also $25 \%$ of chasings between males and $10 \%$ of chasings between females $(\mathrm{F}=17.53, \mathrm{df}=11.00 ; \mathrm{P}<0.01)$. On the hand, $P$. xuthus individuals hardly chased $D$. chrysippus individuals, indicating that $P$. xuthus could identify conspecific butterflies and reject heterogeneous butterflies in nature.

When butterfly mimics were used, results were significant different. The frequency of males chasing female mimics reduced to $19.67 \%$, whereas the frequency of females chasing male mimics increased to $27.9 \%$. On the other hand, the frequency of males chasing male mimics increased to $24.6 \%$, and females chasing female mimics increased to $27.9 \%$ (Fig. 3A). Unlike in the natural population, no significant difference was found among the frequencies of the four types of chasing behavior $(F=0.89, \mathrm{df}=11.00 ; \mathrm{P}$ $>0.05)$. Similarly, $P$. xuthus hardly chased $D$. chrysippus mimics, indicating that $P$. xuthus butterflies identify heterogeneous conspecies butterflies but could not distinguish females and males of their own if only patterns of colors are available.

\section{Analysis of wing color spectrum}

It is very difficult to distinguish females from males of $P$. xuthus because their color and stripes are very similar (Fig. 3B). The color spectrum of wings from both males and females is in the range of visual and ultraviolet light, with only a few differences observed on the ventral surface of the wings (Fig. 3C-D). The results may explain that the butterflies could not recognize their partners by vision alone during courtship.

\section{Body VOCs and their roles in courtship}

During courtship, chemical cues play important roles in identifying sex partners in insects, especially in butterflies because females and males of butterflies are very similar in patterns of both color and shape. To examine potential chemical cues, we measured 29 VOCs obtained from P. Xuthus individuals. The 29 VOCs belonged to 11 different categories. No gender-specific VOCs were observed in either females or males. The top three categories of the identified VOCs included alcohols ( $\nabla 38.39 \% ; \otimes 37.52 \%$ ) and esters ( $\varangle 34.19 \% ; \varangle 32.15 \%)$ (Table 1). We selected three abundant chemicals, 2-ethylhexanol (alcohol), 2ethylhexyl acetate (ester) and the aromatic a-farnesene, to test their ability to attract butterflies during courtship. The total number of males chasing mimics increased significantly after the mimics were sprayed the three chemicals, while no significant change was observed in the number of females chasing mimics after similar spraying (Fig. 4A). Again $P$. Xuthus butterflies hardly chased $D$. chrysippus mimics when the three VOCs were applied on the mimics (Fig. 4A-B), suggesting that patterns of colors were the main cues in identifying heterologous conspecies butterflies.

Butterflies chased butterfly mimics in a way similar to that observed in the natural population during courtship after the mimics were sprayed with a-farnesene (Fig. 4B). The abundance of a-farnesene in females was higher than that in males 3-5 days after emergence (Fig. 4C). The high abundance of afarnesene might be responsible for distinguishing males from females in natural butterfly populations. Application of the other two volatiles resulted in increased total number of chasing but did not result in increased chasing between different sex partners specifically, suggesting that a-farnesene could be a 
chemical cue for distinguishing males from females, whereas 2-ethylhexanol and 2-ethylhexyl acetate could be cues for distinguishing $P$. Xuthus from other butterfly species.

\section{Discussion}

Lepidopterans generally use multi-modal sensory cues during nectar foraging, but the integration of such cues may be complex and hierarchical ${ }^{25}{ }^{2}$ pointed out that there are four types of signal perception during butterfly foraging and courtship, including perception based predominantly on vision, perception based predominantly on olfaction, perception based equally on vision and olfaction, and perception based on olfaction alone. To examine the signal perception mechanism of the butterfly $P$. Xuthus, we tested the responses of $P$. xuthus to visual cues, chemical cues, and the combination of visual and chemical cues. We found that $P$. xuthus used primarily visual cues during flower visits when visual cues and chemical cues were separated. However, synergism was observed when visual and chemical cues were present together during flower visits. Using visual cues as the predominant signals during foraging by butterflies may be due to colorful flowers are easy to identify in nature. On the other hand, chemical cues from VOCs in nature are abundant, complex, and unstable, which may need to invest more genetic resource to identify and distinguish the information from various VOCs. Butterflies may have gradually evolved and developed visual perception as the main signal recognition due to its less genetic cost.

Similarly, butterflies use a variety of visual and chemical cues to identify opposite sex during courtship ${ }^{26-}$ 28. Most butterflies first use visual signals to distinguish females and males, and then use chemical signals to differentiate them further ${ }^{27,29}$. Our results indicated that visual perception of $P$. xuthus outclassed its olfactory perception during courtship. P. xuthus could accurately distinguish individual butterflies from other species solely based on visual cues. However, visual cues were not enough to distinguish males from females of its own species, likely due to very similar colors and patterns of wings on both $P$. xuthus males and females. The frequency of males chasing females was only $19 \%$ in the absence of chemicals. The frequency of males chasing females increased to $40 \%$ when honey water was applied, suggesting that chemical cues played an important role in identification of opposite sex during courtship.

Possible chemical cues include sex hormones and other body VOCs ${ }^{17-20,30-31}$. Analyses of VOCs on the butterfly $P$. xuthus identified several abundant VOCs, which could play roles in identification of mates during courtship. Even though sex-specific VOCs were not identified, several VOCs with quantitative differences between males and females were found. The quantitative differences in VOCs might serve as cues for chemical perception during mating. Indeed, application of two abundant VOCs, 2-ethylhexanol and 2-ethylhexyl acetate, resulted in increased total courtship chases among $P$. Xuthus individuals. Application of the aromatic volatile a-farnesene resulted in increased frequency of males chasing females specifically. These three chemicals exhibited no effects on chasing by $P$. xuthus to $D$. chrysippus butterflies. These observations indicated that chemical cues play important roles in distinguishing butterflies from different species, and between males and females from the same species. 


\section{Materials And Methods}

No specific permits were required for the field studies described.

Test site: Observation was carried out in a net house $(8 \times 8 \times 5 \mathrm{~m})$ in Kunming $\left(102^{\circ} 45^{\prime} \mathrm{E}, 25^{\circ} 03^{\prime} \mathrm{N}\right)$, Yunnan Province, southwestern China. The altitude was $1930 \mathrm{~m}$. Annual average temperature was 15-16 ${ }^{\circ} \mathrm{C}$. Annual average rainfall was $900-1000 \mathrm{~mm}$.

Test butterfly: Papilio xuthus was obtained from artificial breeding populations and used for the observation.

Artificial flowers: Artificial cotton flowers of seven colors were used for the test. The seven colors were red, orange, yellow, blue, purple, green, and white corolla. The size $(8.56 \pm 0.18 \mathrm{~cm}$ in diameter and $2.73 \pm 0.04$ $\mathrm{cm}$ in depth; Fig. 1A) and shape of the artificial flowers were the same. A spectrometer (USB2000+, Ocean Optics, Inc., USA) was used to measure the reflection spectrum of flower colors. The spectrometer was calibrated against a MgO-coated surface as a reference and the spectral reflection of the fake flowers was in the wavelength range of $379-780 \mathrm{~nm}$ (Fig. 1B)

Butterfly mimics: Artificial butterfly wings were adhered to an insect body made of black wooden strips. Butterfly mimics were wrapped in transparent plastic film. The butterfly mimics were the same in size as natural butterflies.

Reflection measurements of natural butterflies and butterfly mimics: The reflection characteristics of natural butterflies and butterfly mimics were measured using a USB2000+ spectrometer with a PX-2 light source (Ocean Optics, Inc., USA). Proofreading was performed for the magnesium oxide surface.

Measurement of color attraction: Seven artificial flowers in a nosegay were placed $0.5 \mathrm{~m}$ above the ground. The distance between adjacent bouquets was $80 \mathrm{~cm}$. Female and male butterflies of $P$. xuthus (20 pairs each) were released into the net house, and their behavior of visiting the fake flowers of seven colors was observed. The position of these flowers was moved clockwise once every $30 \mathrm{~min}$.

Measurement of odor attraction: Corollas from flowers were removed, leaving only their branches and leaves on. Honey water (10\%) was then sprayed on these branches and leaves, and butterfly response to the chemical was examined and recorded.

Measurement of combined impact of both visual and chemical cues: On the artificial flower bouquets, $10 \%$ honey water was sprayed, and flower visits of male and female butterflies were recorded. Honey water was sprayed every hour to avoid its evaporation. All tests were observed continuously for two days.

Observation of visual response behavior during courtship: In the net house, 20 pairs of $P$. xuthus $(\mathbb{\nabla}: \mathbb{Z}=1$ : 1) were released into the net house for observing their courtship behavior for two days. Additionally, 10 pairs of another butterfly species, Danaus chrysippus, were also released to the same net house to determine any inter-species courtship between $P$. xuthus and $D$. chrysippus. 
To separate impact of visual and chemical cues on butterfly behavior during courtship, mimics of $P$. xuthus and $D$. chrysippus were used to test the discrimination of $P$. xuthus based only on butterfly mimic

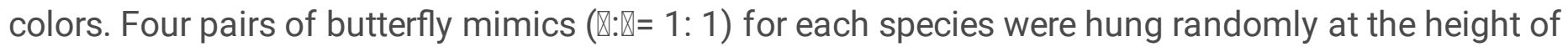
$1.5 \sim 2.0 \mathrm{~m}$ above the ground with $80 \mathrm{~cm}$ apart from each other. Then 20 pairs of virgin $P$. xuthus butterflies $(\mathbb{\nabla}: \mathbb{Z}=1: 1)$ were released into the net house and their chasing behavior toward the mimics was recorded. The mimics were rotated clockwise every $30 \mathrm{~min}$. All tests were observed continuously for 2 days.

Measurement of volatile organic chemicals (VOCs): To measure the impact of volatiles, the method solidphase microextraction (SPME) was used to extract VOCs from female and male butterflies separately. Samples were then analyzed using GC-MS (Thermo Scientific TRACE GC ULTRA and Thermo Scientific ITQ 900 MS; Borg-Karlson \& Mozuraitis, 1996). Three days after eclosion when mating started, P. xuthus individuals were put into an $80 \mathrm{~mL}$ wide mouth bottle. A PDMS/DVB extraction needle with $65 \mu \mathrm{m}$ diameter (Supelco, Bellefonte, PA, USA) was then inserted into the bottle for $1 \mathrm{~h}$. A SPME extraction needle was inserted at the GC inlet $\left(250^{\circ} \mathrm{C}, 10 \mathrm{~min}\right)$ before GC-MS analysis. A TR-5MS column, with inner diameter $0.25 \mathrm{~mm}$, thickness $0.25 \mu \mathrm{m}$, and length $30 \mathrm{~m}$, was used to analyze VOCs. The program for GCMS analysis was $2 \mathrm{~min}$ at $40^{\circ} \mathrm{C}, 2 \mathrm{~min}$ at $120^{\circ} \mathrm{C}$ (achieved by heating at $4{ }^{\circ} \mathrm{C} / \mathrm{min}$ ), and $5 \mathrm{~min}$ at $230^{\circ} \mathrm{C}$ (by heating $5{ }^{\circ} \mathrm{C} / \mathrm{min}$ ). The inlet temperature was $250^{\circ} \mathrm{C}$ and the pressure of the carrier gas He was 69 $\mathrm{kPa}$.

Identification of VOCs was carried out by searching National Library of Standards and Technology (NIST, http://webbook.nist.gov/chemistry/) library combined with manual analysis of mass spectra. Retention indices were calculated and compared with corresponding values in the literature. The retention index (linear retention index, LRI or RI) was calculated as follows (Li 2017):

$$
L R I=100 \times n+\frac{100 \times\left(t_{x}-t_{n}\right)}{t_{n+1}-t_{n}}
$$

LRI-retention index;

$t_{x}$-retention time of the component to be tested (min);

$t_{n}$-retention time of $\mathrm{n}$-alkanes with $\mathrm{n}$ carbon atoms $(\min )$;

$t_{n+1}-$ Retention time of $\mathrm{n}$-alkanes with $\mathrm{n}+1$ carbon atoms(min).

The area normalization method was used to determine the relative content of each volatile compound.

\section{Analysis of selected VOCs on butterfly behavior}


Three most abundant chemicals, 2-ethylhexanol (alcohol), 2-ethylhexyl acetate (ester), and a-farnesene (aromatic), were chosen for analysis of their impact on butterfly males and females. A $1 \%$ solution of each chemical was prepared and $0.5 \mathrm{~mL}$ of each solution was injected into a $0.6 \mathrm{~mL}$ finger tube that was attached to a butterfly mimic. Butterfly mimics were hung $1.8 \mathrm{~m}$ above the ground in the net house. Each mimic was placed one meter apart from each other. Twenty pairs of virgin butterflies three days after eclosion were released into the net house. Their chase behavior toward the butterfly mimics was observed and recorded. Butterfly mimics without chemicals were used as controls. Mimics of $D$. chrysippus were also used for observation of possible inter-species attraction.

\section{Data analysis}

The SPSS 18.0 software was used for data analysis. One-way ANOVA was used to identify significant differences during foraging and courtship events between males and females.

\section{Declarations}

\section{Acknowledgements}

We would like to thank Ming Tao Li for his participation in field observations, and also Professor Xiao Ming Chen for reviewing and improving the manuscript.

\section{Author Contributions}

X.M.C. designed the project with intellectual contributions from all authors; J.L. collected, analyzed the data and wrote the paper; all authors reviewed the final manuscript.

\section{Competing Interests}

The authors declare no competing interests.

\section{Data availability}

All data sets generated during and/or analyzed during the current study are available from the corresponding author on reasonable request.

\section{Additional information}

Correspondence and requests for materials should be addressed to XM. C.

Reprints and permissions information is available at www.nature.com/reprints.

Publisher's note Springer Nature remains neutral with regard to jurisdictional claims in published maps and institutional afliations. 
Open Access Tis article is licensed under a Creative Commons Attribution 4.0 International License, which permits use, sharing, adaptation, distribution and reproduction in any medium or format, as long as you give appropriate credit to the original author(s) and the source, provide a link to the Creative Commons licence, and indicate if changes were made. Te images or other third party material in this article are included in the article's Creative Commons licence, unless indicated otherwise in a credit line to the material. If material is not included in the article's Creative Commons licence and your intended use is not permitted by statutory regulation or exceeds the permitted use, you will need to obtain permission directly from the copyright holder. To view a copy of this licence, visit http://creativecommons.org/licenses/by/4.0/.

\section{References}

1. Briscoe, A. D. Reconstructing the ancestral butterfly eye, focus on the opsins. J. Exp. Biol. 211, 18051813 (2008).

2. Tang, Y. C., Zhou, C. L., Chen, X. M. \& Zheng, H. Visual and olfactory responses of seven butterfly species during foraging. J. Insect Behav. 26, 387-401 (2013).

3. Ilse, D. \& Vaidya, V. G. Spontaneous feeding response to colours inPapilio demoleus L, pp. 23-31. In, Proceedings of the Indian Academy of Sciences-Section B. Springer (1956).

4. Swihart, S. L. The neural basis of colour vision in the butterfly, Papilio troilus. J. Insect Physiol. 16, 1623-1636 (1970).

5. Scherer, C. \& Kolb, G. The influence of color stimuli on visually controlled behavior in Aglais urticae $L$. and Pararge aegeria L.(Lepidoptera). J. Comp. Physiol. A 161, 891-898 (1987b).

6. Scherer, C. \& Kolb, G. Behavioral experiments on the visual processing of color stimuli in Pieris brassicae L.(Lepidoptera). J. Comp. Physiol. A 160, 645-656 (1987a).

7. Scherer, C. \& Kolb, G. The influence of color stimuli on visually controlled behavior in Aglais urticae L. and Pararge aegeria L.(Lepidoptera). Journal of Comparative Physiology A, 161, 891-898. (1987b).

8. Tiple, A. D., Deshmukh, V. P. \& Dennis, R. L. Factors influencing nectar plant resource visits by butterflies on a university campus, implications for conservation. Nota Lepidopterol. 28, 213-224 (2005).

9. Stavenga, D. G. \& Arikawa, K. Evolution of color and vision of butterflies. Arthropod. Struct. Dev. 35, 307-318 (2006).

10. Li, C. Z. The recognition mechanism of sexual mating based on the adult behavior of butterflies and the construction of butterfly flying landscape. PhD, Chinese Academy of Forestry (2017).

11. Obara, Y. \& Majerus, M. E. Initial mate recognition in the British cabbage butterfly, Pieris rapae rapae. Sci. 17, 725-730 (2000).

12. Sweeney, A., Jiggins, C. \& Johnsen, S. Polarized light as a butterfly mating signal. Nature 423, 31-32 (2003).

13. Ilse, D. Über den farbensinn der Tagfalter. Vgl. Physiol. 8, 658-692 (1928). 
14. Bergstrom G, \& Pellmyrt, O. Floral fragrances in Cimicifuga, chemical polymorphism and incipient speciation in Cimicifuga simplex. Syst. Ecol. 15, 441-444 (1987).

15. Honda, K., Ômura, H. \& Hayashi, N. Identification of floral volatiles from Ligustrum japonicum that stimulate flower-visiting by cabbage butterfly, Pieris rapae. J. Chem. Ecol. 24, 2167-2180 (1998).

16. Groth, I., Bergström, G. \& Pellmyr, O. Floral fragrances in Cimicifuga, Chemical polymorphism and incipient speciation in Cimicifuga simplex. Biochem. Syst. Ecol. 15, 441-444 (1987).

17. Edgar, J., Boppré, M. \& Schneider, D. Pyrrolizidine alkaloid storage in African and Australian danaid butterflies. Mol. Life Sci. 35, 1447-1448 (1979).

18. Kelley, R., Seiber, J., Jones, A., Segall, H., \& Brower, L. Pyrrolizidine alkaloids in overwintering monarch butterflies (Danaus plexippus) from Cell. Mol. Life Sci. 43, 943-946 (1987).

19. Andersson, S. \& Dobson, H. E. Behavioral foraging responses by the butterfly Heliconius melpomene to Lantana camara floral scent. Chem. Ecol. 29, 2303-2318 (2003).

20. Schulz, S., Estrada, C., Yildizhan, S., Boppré, M. \& Gilbert, L. E. An antiaphrodisiac in Heliconius melpomene J. Chem. Ecol. 34, 82-93 (2008).

21. KonDo, Y., Naka, H., \& Tsuchida, K. Pheromones and body coloration affect mate recognition in the Japanese nine-spotted moth Amata fortunei (Lepidoptera, Arctiidae). Ethol. 30, 301-308 (2012).

22. Pinzari, M. \& Sbordoni, V. Species and mate recognition in two sympatric Grayling butterflies, Hipparchia fagi and hermione genava (Lepidoptera). Ethol. Ecol. Evol 25, 28-51 (2013).

23. Krishnan, A., Joshi, K. A. \& Abraham, A. Finding hidden females in a crowd, Mate recognition in fig wasps. Acta Oecol. 57, 80-87 (2014).

24. Ômura, H. Foraging behavior of adult butterflies and its semiochemicals as olfactory signals. Comparative Physiology and Biochemistry 23, 134-142 (2006).

25. Goyret, J., Markwell, P. M. \& Raguso, R. A. The effect of decoupling olfactory and visual stimuli on the foraging behavior of Manduca sexta. Exp. Biol. 210, 1398-1405 (2007).

26. Wago, H. Studies on the mating behavior of the pale grass blue, Zizeeria maha argia (Lepidoptera, Lycaenidae) III. Olfactory cues in sexual discrimination by males. Entomol. Zool. 13, 283-289 (1978).

27. Costanzo, K. \& Monteiro, A. The use of chemical and visual cues in female choice in the butterfly Bicyclus anynana. R. Soc. B 274, 845-851 (2007).

28. Rutowski, R. L. \& Rajyaguru, P. K. Male-specific iridescent coloration in the pipevine swallowtail (Battus philenor) is used in mate choice by females but not sexual discrimination by males. Insect. Behav. 26, 200-211 (2013).

29. Scott, J. A. Mating of butterflies. Res. Lepid. 11, 99-127 (1973).

30. Pliske, T. E. Courtship behavior and use of chemical communication by males of certain species of ithomiine butterflies (Nymphalidae, Lepidoptera). Entomol. Soc. Am. 68, 935-942 (1975).

31. Li, C. Z. The recognition mechanism of sexual mating based on the adult behavior of butterflies and the construction of butterfly flying landscape. PhD, Chinese Academy of Forestry (2017). 


\section{Tables}

Table 1 Classification of VOCs in the adults of $P$. xuthus

\begin{tabular}{|lll|}
\hline VOCs & \multicolumn{2}{l|}{ Contents $\$$ $\%$} \\
\cline { 2 - 3 } & $\square$ & $\square$ \\
\hline Alkanes & 6.91 & 6.05 \\
\hline Alkynes & 0.48 & 0.31 \\
\hline Terpenes & 4.65 & 10.54 \\
\hline Alcohols & 38.39 & 37.52 \\
\hline Ethers & 7.39 & 7.1 \\
\hline Aldehydes & 1.60 & 0.25 \\
\hline Ketones & 1.31 & 1.24 \\
\hline heterocycles & 0.37 & 0.32 \\
\hline Acids & 3.65 & 3.45 \\
\hline Esters & 34.19 & 32.15 \\
\hline Arenes & 1.06 & 1.07 \\
\hline
\end{tabular}

Figures 

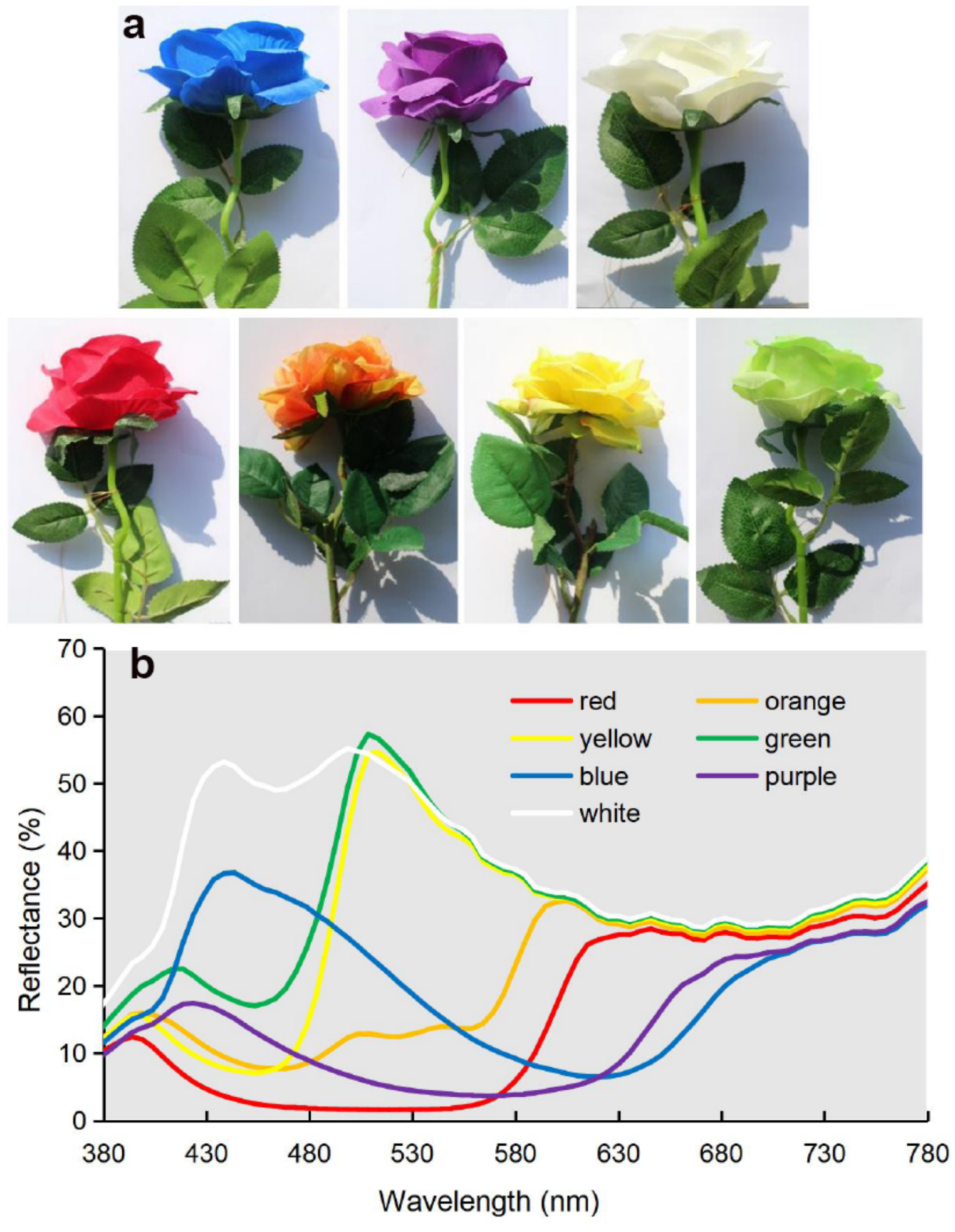

Figure 1

Artificial flowers and their spectral reflectance. A. Artificial flowers with seven colors; B. Spectral reflectance of the seven colors 

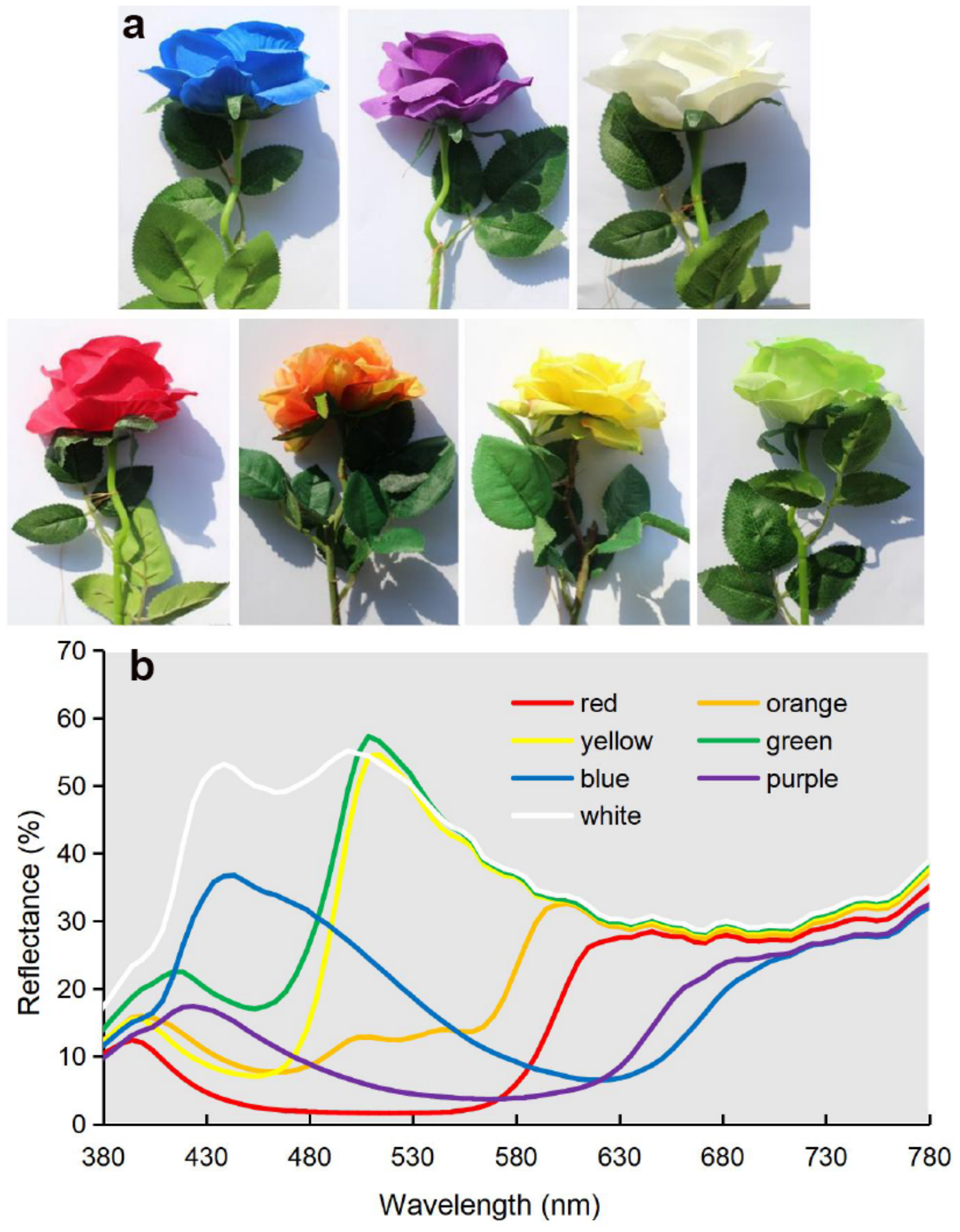

Figure 1

Artificial flowers and their spectral reflectance. A. Artificial flowers with seven colors; B. Spectral reflectance of the seven colors 

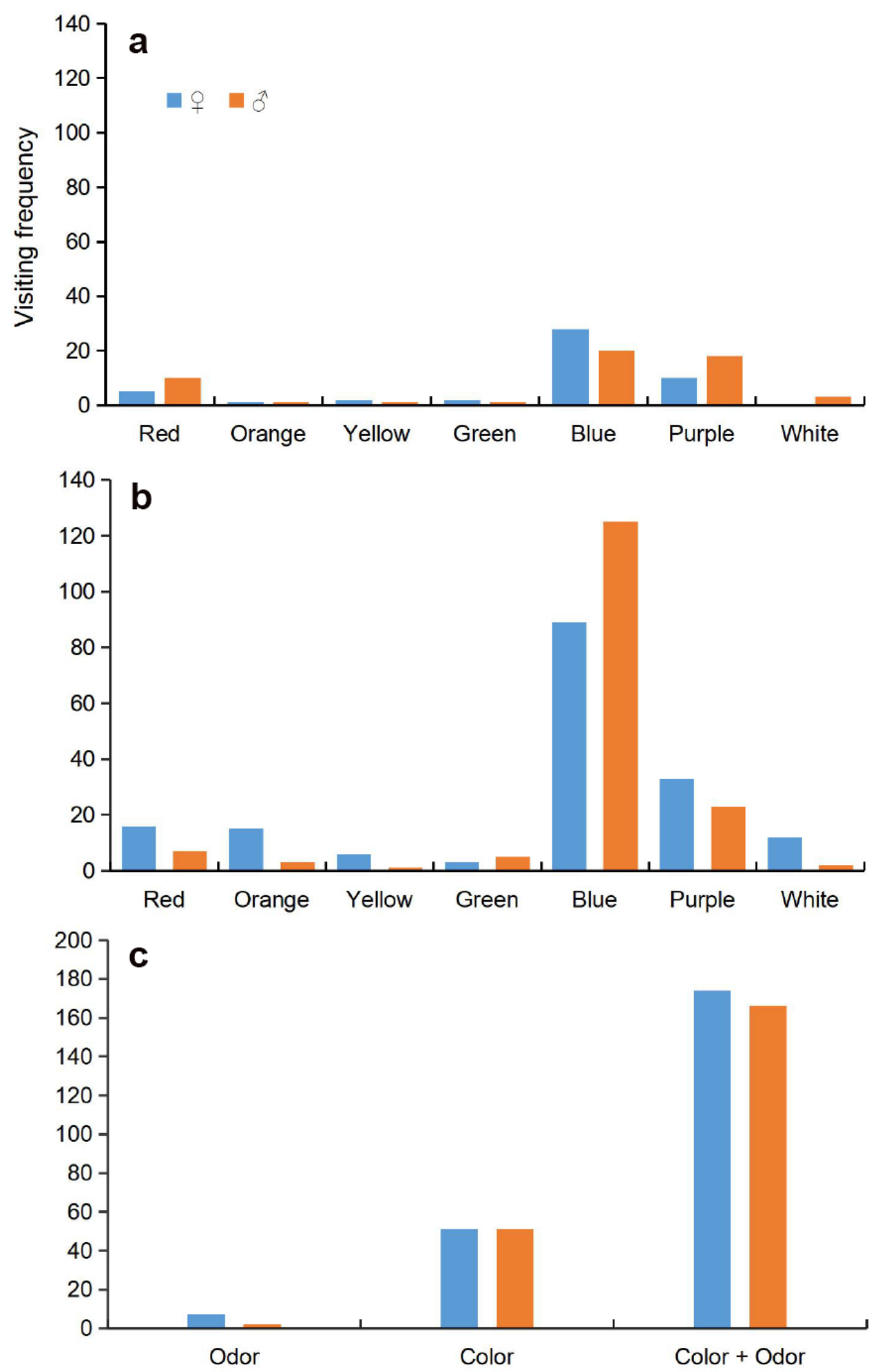

Figure 2

Response of the butterfly P. xuthus to artificial flowers with different colors and combination of different colors and odors. A. Response of P. xuthus to flowers with different colors. B. Response of P. xuthus to flowers sprayed with $10 \%$ honey water. C. Synergistic effects of colors and odor on butterfly behavior. 

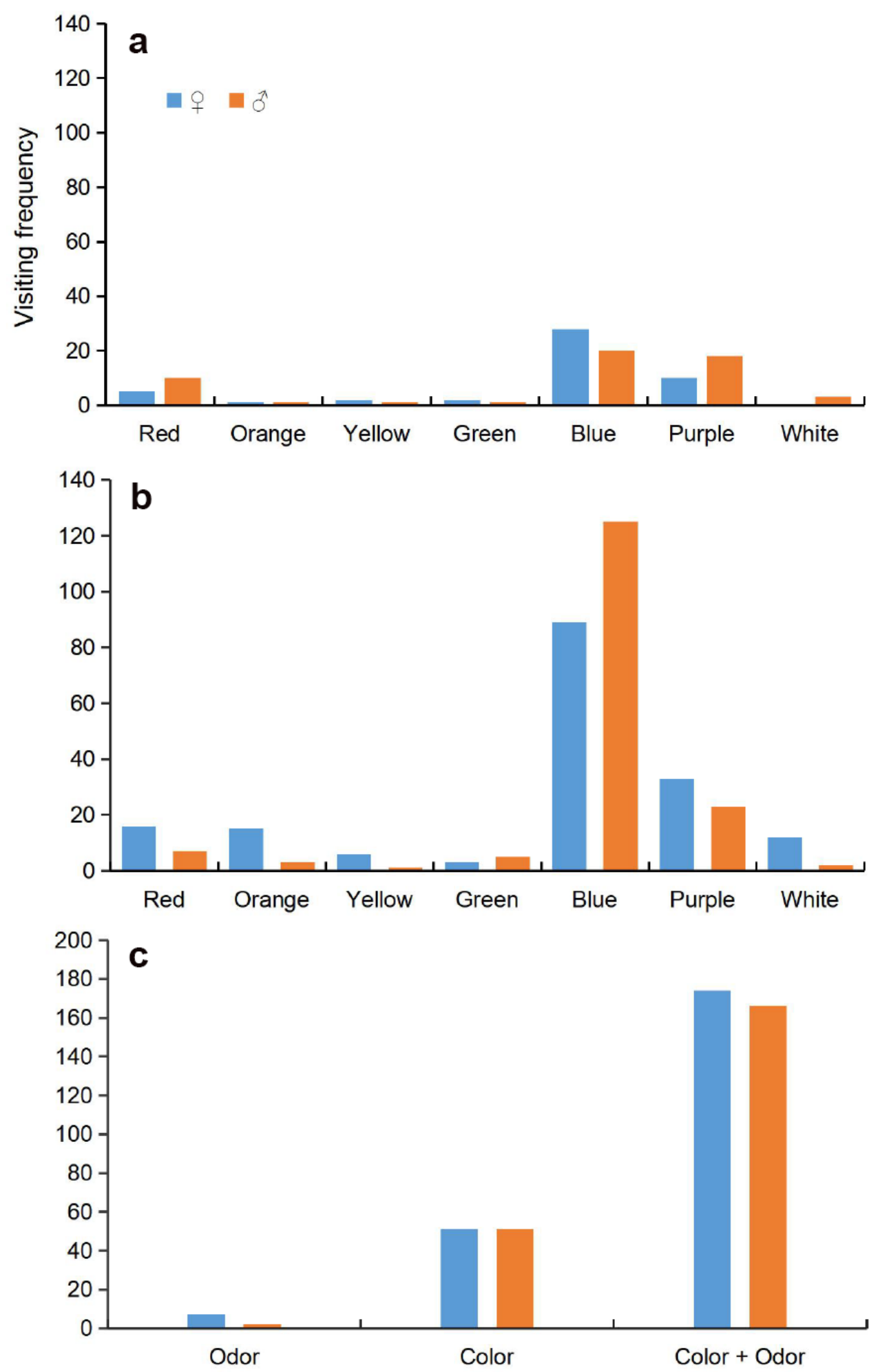

Figure 2

Response of the butterfly P. xuthus to artificial flowers with different colors and combination of different colors and odors. A. Response of P. xuthus to flowers with different colors. B. Response of P. xuthus to flowers sprayed with $10 \%$ honey water. C. Synergistic effects of colors and odor on butterfly behavior. 

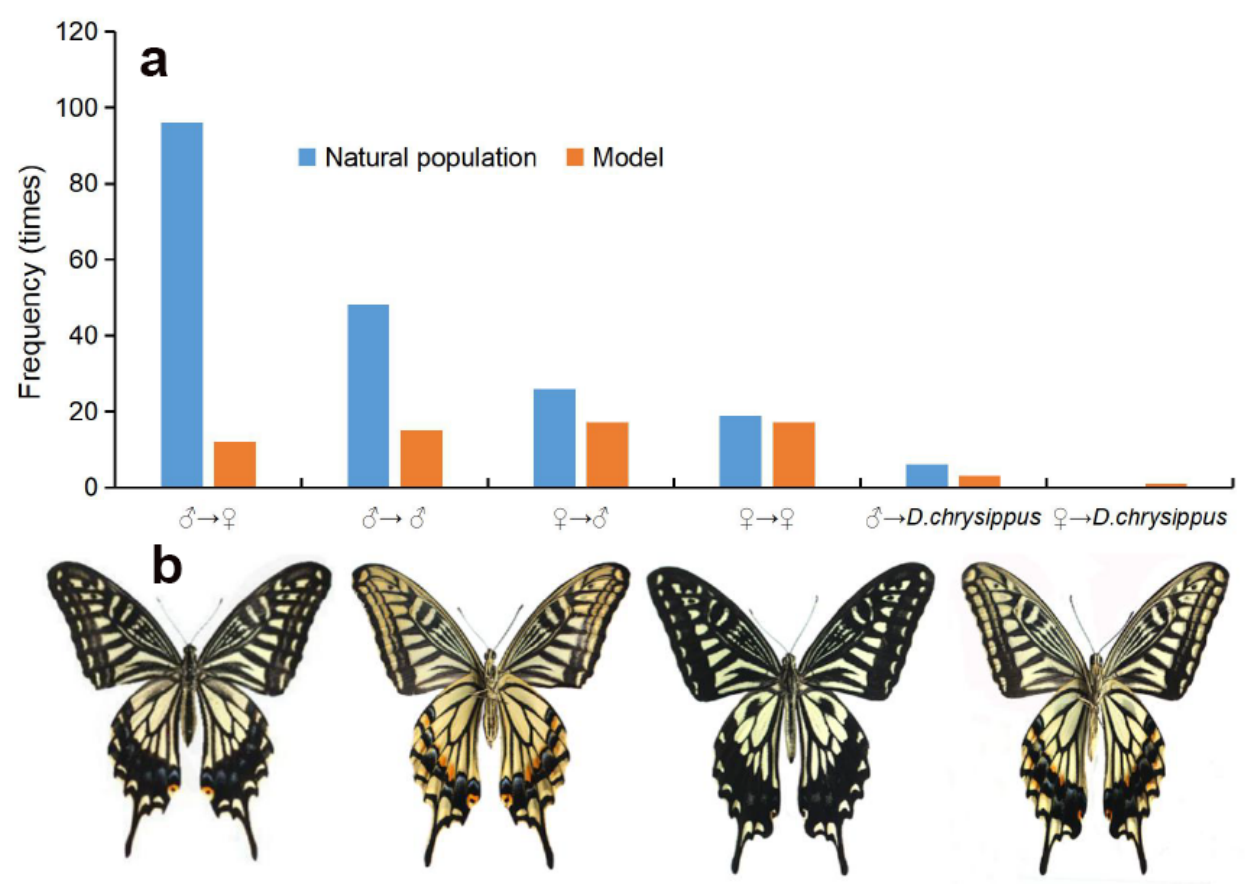

$$
\text { q dorsal } q \text { ventral } \delta \text { dorsal } \delta \text { ventral }
$$

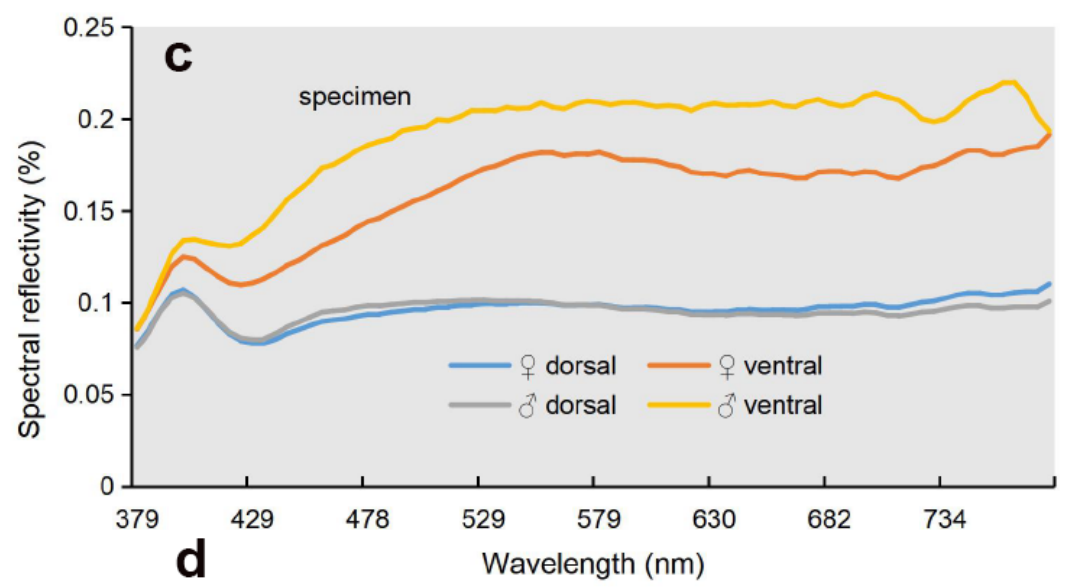

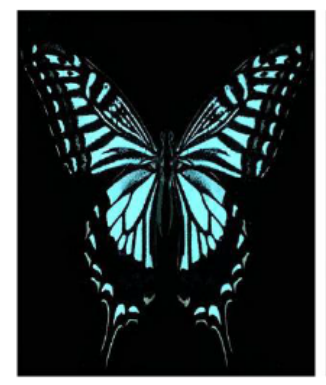

ㅇ dorsal

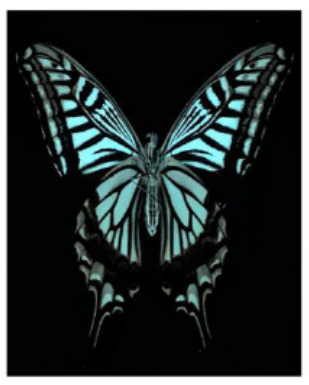

q ventral

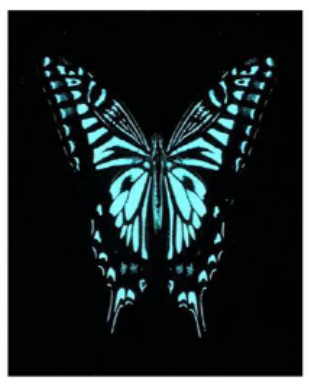

$\delta$ dorsal

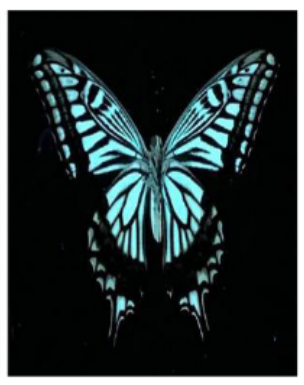

$\delta$ ventral

\section{Figure 3}

Chase behavior of $P$. xuthus during courtship and wing reflection spectrum. A. Chase behavior of $P$. xuthus during courtship using both natural butterflies and butterfly mimics. B. Representative butterfly specimen under natural light. C. Reflective spectrum of the butterfly specimen. D. Images of butterfly specimen under UV light. 

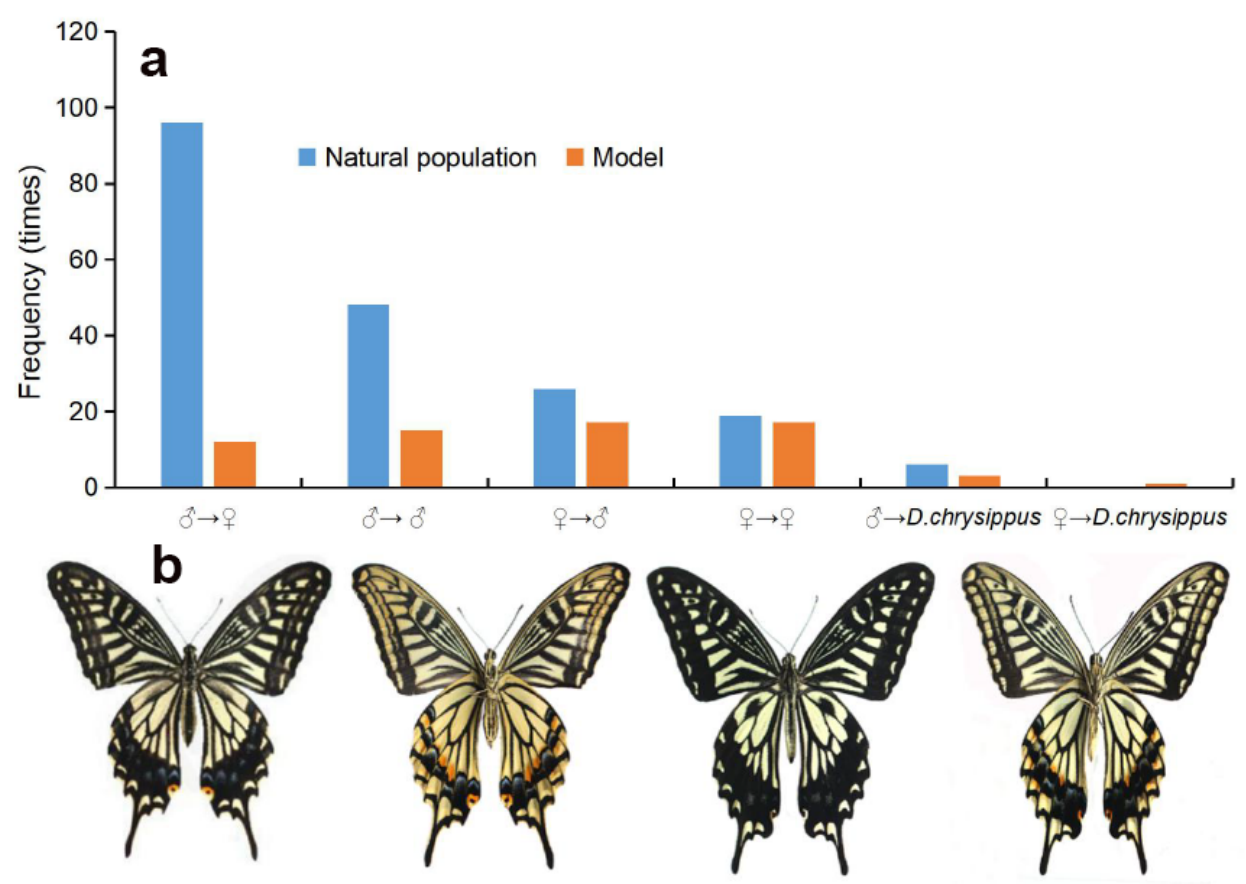

$$
\text { q dorsal } q \text { ventral } \delta \text { dorsal } \delta \text { ventral }
$$

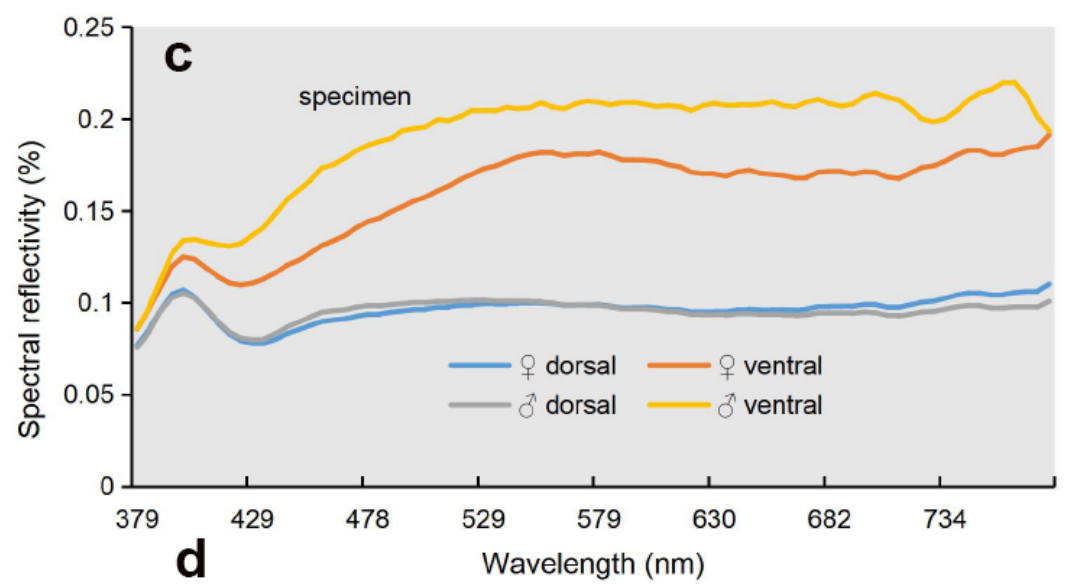

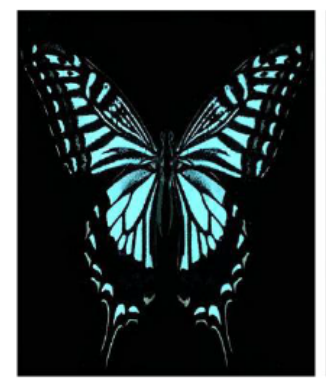

ㅇ dorsal

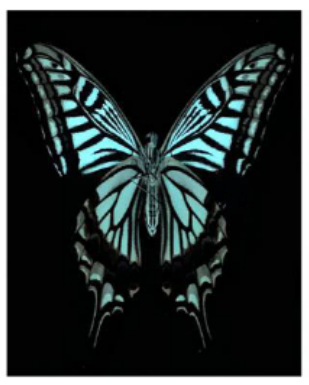

q ventral

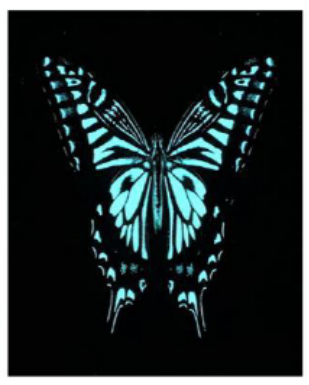

$\delta$ dorsal

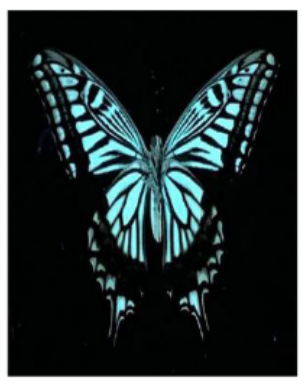

$\delta$ ventral

\section{Figure 3}

Chase behavior of $P$. xuthus during courtship and wing reflection spectrum. A. Chase behavior of $P$. xuthus during courtship using both natural butterflies and butterfly mimics. B. Representative butterfly specimen under natural light. C. Reflective spectrum of the butterfly specimen. D. Images of butterfly specimen under UV light. 

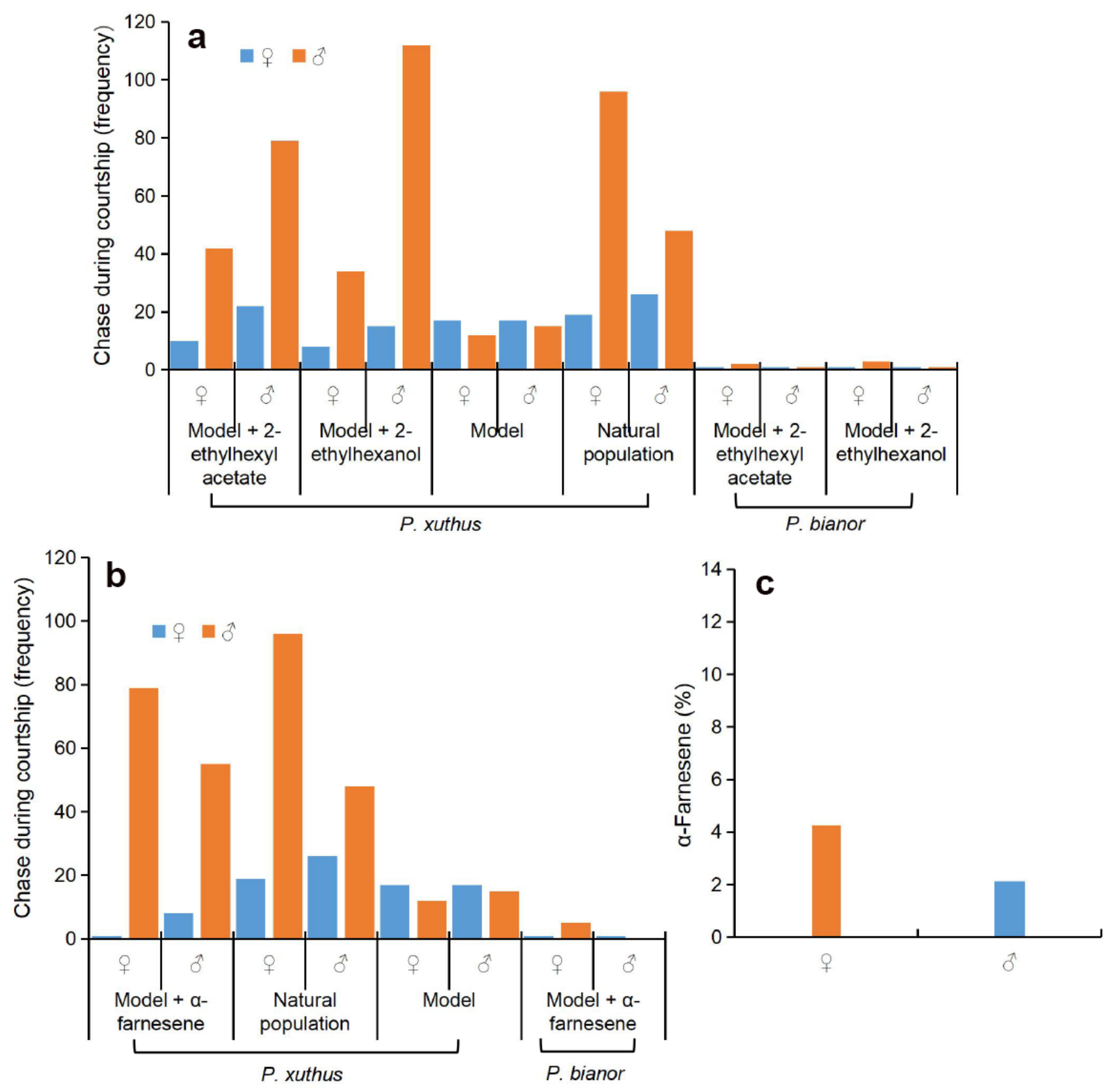

Figure 4

Chasing behavior of the butterfly P. xuthus to VOCs during courtship. A. Chasing frequency between males and females to butterfly mimics applied with 2-ethylhexyl acetate and 2-ethyl-1-hexanol. B. Impact of a-Farnesene on chasing behavior of the butterflies P. xuthus and P. bianor. C. Abundance of $\mathrm{a}-$ farnesene in females and males of P. xuthus. 

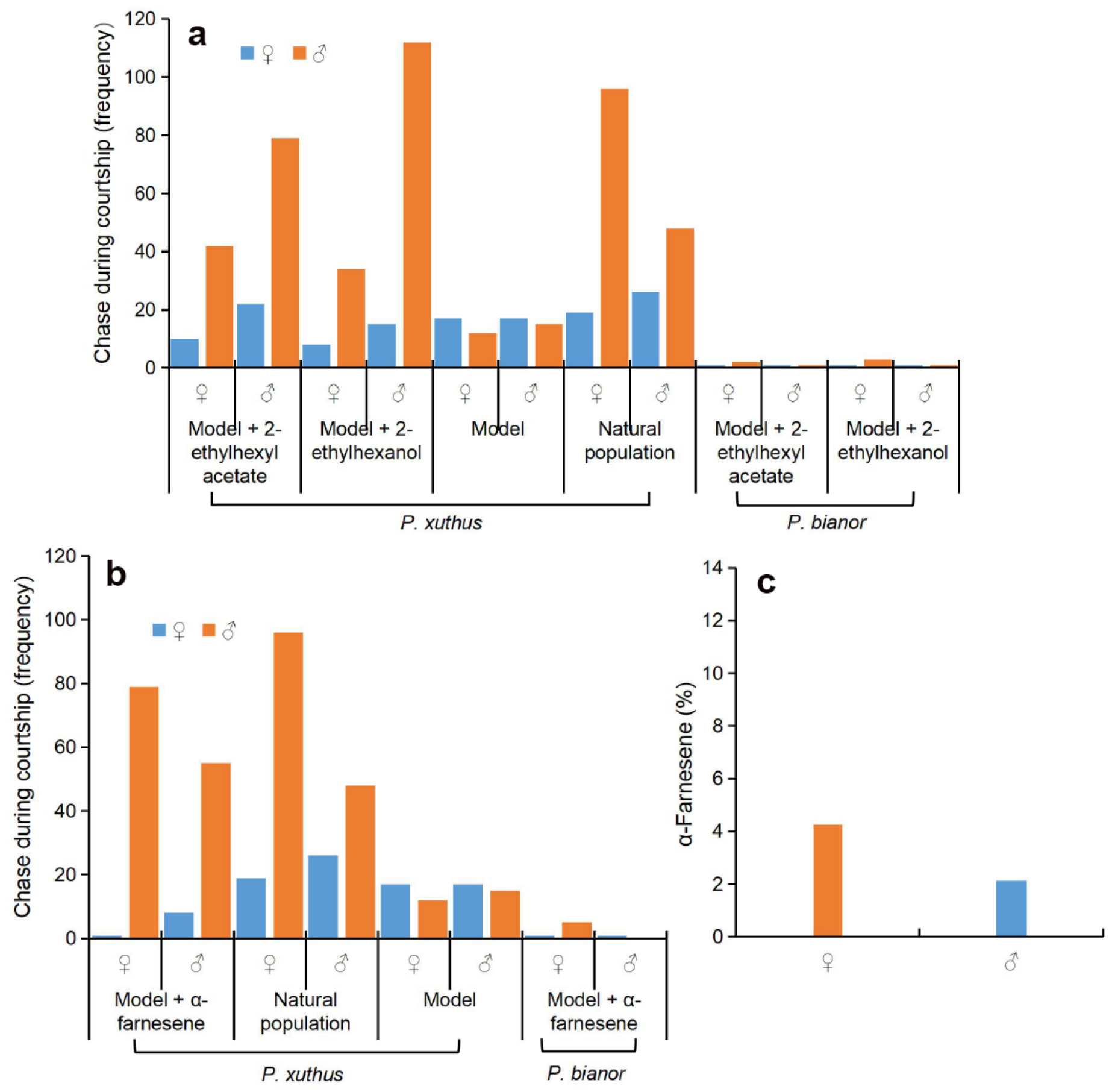

Figure 4

Chasing behavior of the butterfly P. xuthus to VOCs during courtship. A. Chasing frequency between males and females to butterfly mimics applied with 2-ethylhexyl acetate and 2-ethyl-1-hexanol. B. Impact of a-Farnesene on chasing behavior of the butterflies P. xuthus and P. bianor. C. Abundance of $\mathrm{a}-$ farnesene in females and males of P. xuthus. 